\title{
Experimental investigation of the tribological behaviour of carbon and low-alloy steels sliding against HSS
}

\author{
Riadh Autay ${ }^{a}$, Mounir Kchaou and Fakhreddine Dammak \\ Laboratory of Mechanics, Modeling and Production (LA2MP), National Engineering School of Sfax, University of Sfax, \\ Route Soukra km 3.5, B.P 1173, 3038 Sfax, Tunisia
}

Received 29 June 2014, Accepted 18 September 2014

\begin{abstract}
ISO 42CrMo4 low-alloy steel and ISO C45 carbon steel are commonly used in the manufacture of mechanical parts, which are continuously subjected to friction and wear. The effect of microstructure changes during functioning on the tribological behaviour of these steels was evaluated under unlubricated and reciprocating sliding conditions. The diverse microstructures are obtained by varying the heat treatment conditions. The mechanical behaviour of the diverse obtained microstructures was investigated via hardness measurements and tensile tests. Results showed that there is no correlation between friction properties and mechanical ones. Wear properties depend on hardness but no correlation is obtained between wear properties and work hardening ones. Increasing normal load decreased friction properties but increased wear properties.
\end{abstract}

Key words: Low-alloy steel / carbon steel / microstructure / hardness / friction coefficient / friction energy / wear volume / wear coefficient

\section{Nomenclature}

\begin{tabular}{|ll|}
\hline$A \%$ & Elongation at break (\%) \\
$b$ & Worn track width (mm) \\
$D$ & Cylinder diameter (mm) \\
$E$ & Total energy (J) \\
$F$ & Applied load (N) \\
$F_{\mathrm{n}}$ & Normal force (N) \\
$F_{\mathrm{t}}$ & Friction force (N) \\
$H V$ & Vickers hardness of studied steel (N.mm ${ }^{-2}$ ) \\
$K$ & Archard wear coefficient (dimensionless) \\
$L$ & Sliding distance (mm) \\
$n$ & Work hardening coefficient (dimensionless) \\
$R_{m}$ & Ultimate strength (MPa) \\
$R p_{0.2}$ & Offset yield strength or proof stress (MPa) \\
$R_{m}-R_{p 0.2}$ & Hardening capacity (MPa) \\
$l$ & Worn track length (mm) \\
$v$ & Average sliding speed (m.s ${ }^{-1}$ ) \\
$V$ & Worn volume (mm ${ }^{3}$ ) \\
$Z \%$ & Reduction in cross sectional area (\%) \\
$Z_{u} \%$ & Elongation due to necking (\%) \\
$\mu$ & Friction coefficient (dimensionless) \\
\hline
\end{tabular}

\footnotetext{
${ }^{a}$ Corresponding author: riadh.autay@enis.rnu.tn
}

\section{Introduction}

When two surfaces are in relative sliding most of the friction work is converted into heat. The significant rise in temperature can change the metallurgical and mechanical properties of sliding surfaces and eventually their tribological behaviour. Predicting the impact of microstructural changes on friction and wear behaviours can be performed by a tribological study of some typical microstructures obtained via different heat treatment methods. Rai et al. [1] studied wear behaviour of different microstructures of Ni-Cr-Mo-V steel, and considered that such study may provide a better understanding of the basic modes and mechanisms of wear and help in proper selection of typical-structured-steel for particular application. Shaeri et al. [2] investigated the effect of austempering and martempering heat treatments on wear behaviour of Cr-Mo steel (FMU-226). Das et al. [3] studied AISI D2 steel and attempted to correlate microstructure with wear behaviour of deep cryogenically treated specimens with reference to that of conventional heat treatment and cold treatment. Kumar et al. [4] studied the effect of two microstructures (fine pearlite with small amount of ferrite and tempered martensite with cementite) on wear behaviour of a medium carbon steel. Abouei et al. [5] compared wear and friction characteristics of a plain carbon dual phase steel (hard martensite island embedded in a 
R. Autay et al.: Mechanics \& Industry 16, 109 (2015)

Table 1. Chemical compositions of as-received steels and HSS (wt. \%).

\begin{tabular}{ccccccccccccc}
\hline & $\mathrm{C}$ & $\mathrm{Mn}$ & $\mathrm{Si}$ & $\mathrm{S}$ & $\mathrm{P}$ & $\mathrm{Cr}$ & $\mathrm{Mo}$ & $\mathrm{Ni}$ & $\mathrm{Cu}$ & $\mathrm{Al}$ & $\mathrm{V}$ & $\mathrm{W}$ \\
\hline $\mathrm{C} 45$ & 0.45 & 0.76 & 0.34 & 0.036 & 0.034 & 0.19 & 0.019 & 0.056 & 0.043 & 0.021 & - & - \\
42CrMo4 & 0.42 & 0.78 & 0.28 & 0.031 & 0.009 & 0.97 & 0.19 & - & - & - & - & - \\
SW9M2S & 0.95 & 0.4 & 0.7 & $<0.02$ & $<0.02$ & 4.5 & 2 & - & - & - & 1.8 & 9 \\
\hline
\end{tabular}

Table 2. Process conditions and specimens hardnesses.

\begin{tabular}{ccccc}
\hline Methods & Code & Conditions & \multicolumn{2}{c}{ HV } \\
\hline & & & C45 & 42 CrMo4 \\
\hline Untreated & $\mathrm{NT}$ & & 208 & 373 \\
Normalizing & $\mathrm{N}$ & Heating at $870{ }^{\circ} \mathrm{C}$ for $30 \mathrm{~min} /$ Cooling in Air & 210 & 328 \\
Quenching & $\mathrm{WQ}$ & Heating at $850{ }^{\circ} \mathrm{C}$ for $30 \mathrm{~min} /$ Cooling in Water & 608 & 664 \\
Quenching & $\mathrm{OQ}$ & Heating at $850{ }^{\circ} \mathrm{C}$ for $30 \mathrm{~min} /$ Quenching in Oil & 275 & 588 \\
Tempering & $\mathrm{WQT}$ & $\mathrm{WQ} / 200{ }^{\circ} \mathrm{C}$ for $120 \mathrm{~min} /$ Quenching in Air & 538 & 545 \\
Tempering & $\mathrm{OQT}$ & $\mathrm{OQ} / 200{ }^{\circ} \mathrm{C}$ for $120 \mathrm{~min} /$ Quenching in Air & 265 & 496 \\
\hline
\end{tabular}

ductile ferrite matrix) with those observed in plain carbon normalized (pearlite and ferrite) and hardened (martensite structure only) steels. Garcia et al. [6] compared abrasive wear resistance of an austenitic manganese steel subjected to diverse thermal treatments. Wang et al. [7] studied wear behaviour of 52100 and 1080 steels with different microstructures in dry sliding conditions and showed that wear resistance of different microstructures is increased in the following order: martensite + carbide + retained austenite, spheroidized structure (ferrite plus spheroidized cementite), martensite, bainite, lamellar pearlite. In this context, tribological study is conducted on a carbon steel and a low-alloy steel, which are commonly used in the manufacture of mechanical parts such as shafts, bearings, gears, cams [8]... etc. Such mechanical parts have a contact surface continuously evolving over time due to friction and wear. This study is a contribution in the good understanding of the tribological behaviour of such engineering steels when a harder material, such as HSS, is used as counterpart.

\section{Experimental data}

The materials of investigation are the ISO C45 carbon steel and the ISO 42CrMo4 low-alloy steel. HSS (SW9M2S) was employed as counterpart. The reason for utilising HSS as a counter material was essentially its high hardness. The chemical compositions of the three steels are presented in Table 1 . The studied steels were subjected to different heat treatments. The process conditions and the obtained hardnesses are given in $\mathrm{Ta}-$ ble 2. The hardness measurements are carried out on a VH6-L semi-automatic Vickers durometer under load of $10 \mathrm{~N}$ and dwell time of $5 \mathrm{~s}$. Three indentations are made at least for each specimen. The measurements are done along a cross section at different positions and an average value was calculated. After treatments, the specimens were ground, polished and etched with Nital 5\%, in order to obtain suitable surface for their microscopic examination. The microstructure of studied steels was examined using a Carl Zeiss optical microscope. The surface
Table 3. Conditions of the friction tests.

\begin{tabular}{cc}
\hline Normal loads $(\mathrm{N})$ & $22.7 / 42.7 / 62.7$ \\
Hertzian pressures (MPa) & $\approx 59 / 81 / 98$ \\
Frequency of oscillation & $1 \mathrm{~Hz}$ \\
Oscillating stroke & $10 \mathrm{~mm}$ \\
Sliding duration & $\geq 120 \mathrm{~min}$ \\
Acquisition & $32 \mathrm{~s}^{-1}$ \\
Roughness (Ra) & $0.2 \pm 0.05 \mu \mathrm{m}$ \\
Relative humidity & $\approx 40 \%$ \\
\hline
\end{tabular}

roughness was evaluated before and after friction test using a DIAVITE DH-7 profilometer. Tensile tests are carried out using a Lloyd Instruments machine $(50 \mathrm{kN}$ load cell) at $5 \mathrm{~mm} \cdot \mathrm{min}^{-1}$ elongation speed. Three tests were carried out and an average value was calculated for each microstructure. Cylindrical specimens are employed; their shapes and dimensions are taken in accordance with standard NF EN 10002-1. Tensile tests were carried out without using an extensometer. Consequently, a varied elastic modulus is noticed. In this study, we are not interested by elastic modulus, which depends on the elongation (and then the use of an extensometer) but only on the stress characteristics. Tribological tests are carried out, at ambient temperature, on a reciprocating sliding tribometer (Fig. 1) which is designed and manufactured in the research laboratory LA2MP. Dissimilar antagonists were employed. Cylinder-on-flat contact configuration was adopted. This test method employs a flat lower specimen $\left(20 \times 20 \times 12 \mathrm{~mm}^{3}\right)$ made in HSS $(870 \mathrm{HV} 1)$ and an upper stationary cylinder $\left(\phi 16 \times 15 \mathrm{~mm}^{2}\right)$ made of the tested steel, as antagonist. Upper and lower specimens are moving relative to one another in a linear, back and forth sliding motion, under a prescribed set of conditions. The load is applied vertically downward through the upper specimen against the horizontally mounted flat specimen. The selected normal loads are depending on the friction tester capacity. Friction test conditions are summarised in Table 3. The friction coefficient " $\mu$ " is calculated using equation (1):

$$
\mu=F_{\mathrm{t}} / F_{\mathrm{n}}
$$



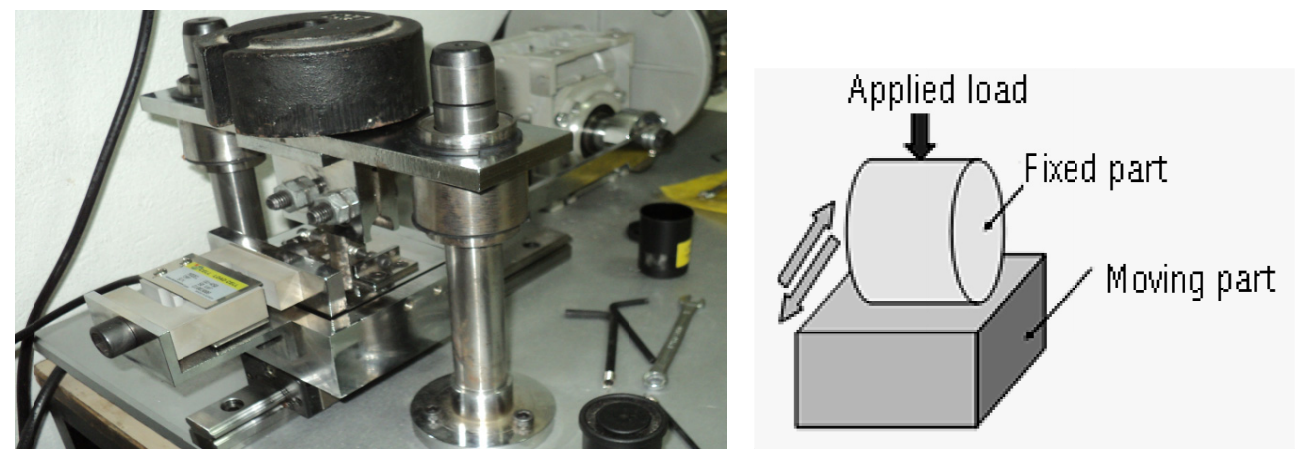

Fig. 1. Reciprocating friction tester and contact configuration.

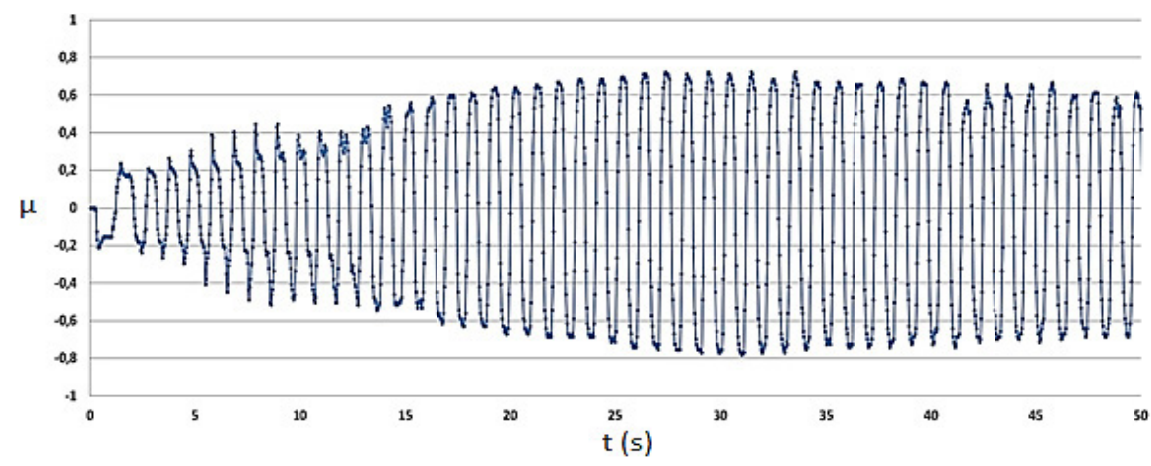

Fig. 2. Sampling of the friction coefficient over the first fifty reciprocating sliding cycles.

with $F_{\mathrm{t}}$ friction force in Newton and $F_{\mathrm{n}}$ normal force in Newton. The dissipated friction energy, $\Delta E$, in the contact is calculated as the work of the friction force [9] using equation (2):

$$
\Delta E=F_{\mathrm{t}} v \Delta t
$$

$v$ is the average sliding speed and $\Delta t$ is the time interval corresponding to the dissipated energy $\Delta E$. The total energy, $E$, dissipated throughout the test can be calculated by adding all the " $\Delta E$ " calculated during the course of the test using the method of trapezoids, equation (3):

$$
E=\frac{1}{2} F_{\mathrm{n}} V \sum\left(\mu_{i}+\mu_{i+1}\right)\left(t_{i+1}-t_{i}\right)
$$

$\mu_{i}$ and $\mu_{i+1}$ represent the coefficients of friction corresponding to test durations $t_{i}$ and $t_{i+1}$. These time intervals are taken each $10 \mathrm{~s}$ for the first $100 \mathrm{~s}$ of test time. Then the time interval was taken every $100 \mathrm{~s}$ until the ending of test duration. This choice is because there is great variation in the value of friction coefficient during the first sliding cycles (period of accommodation) then this friction characteristic becomes relatively stable. Friction coefficient is continuously measured during reciprocating sliding. Fifty subsequent sliding cycles are illustrated in Figure 2 with a positive or negative value depending on sliding direction. One sliding cycle (double sliding stroke) contains 32 sample values. Wear coefficient is determined using Archard formula [10], equation (4):

$$
K=V H V / F L
$$

$V$ is the worn volume $\left(\mathrm{mm}^{3}\right), F$ is the applied load (N), $L$ is the sliding distance ( $\mathrm{mm}), H V$ is the Vickers hardness of studied steel and $K$ is the Archard wear coefficient (adimensional). The worn volume [11] is determined using equation (5):

$$
V=\left(D^{2} \operatorname{Arcsin}\left(\frac{b}{D}\right)-b \sqrt{D^{2}-b^{2}}\right) \frac{l}{4}
$$

The worn volume is determined using mathematical approximations and experimental measures as worn track width " $b$ " (mm), worn track length "l" (mm) and cylinder diameter " $D$ " (mm).

\section{Results and discussion}

\subsection{Microstructure and mechanical behaviour}

The optical micrographs of the various obtained microstructures are illustrated in Figures 3 and 4. Micrographic analysis of $\mathrm{C} 45$ steel showed that the microstructure of untreated samples (NT) was ferrito-pearlitic. The application of normalisation treatment $(\mathrm{N})$ reduced the size of the pearlite grains. The microstructures of the quenched in oil (OQ) and the quenched in oil and tempered samples (OQT) were also pearlitic. The quenched in water (WQ) and the quenched in water and tempered samples (WQT) microstructures were martensitic with retained austenite. Micrographic analysis showed 
R. Autay et al.: Mechanics \& Industry 16, 109 (2015)

Table 4. Strength and ductility properties of specimens.

\begin{tabular}{ccccccccccccc}
\hline \multicolumn{1}{c}{ ISO C45 } & \multicolumn{1}{c}{ ISO 42CrMo4 } \\
\hline & $R p_{0.2}$ & $R_{m}$ & $\mathrm{~A} \%$ & $\mathrm{Zu} \%$ & $\mathrm{Z} \%$ & $n$ & $R p_{0.2}$ & $R_{m}$ & $\mathrm{~A} \%$ & $\mathrm{Zu} \%$ & $\mathrm{Z} \%$ & $n$ \\
\hline NT & 425 & 789 & 26 & 8.5 & 29 & 0.33 & 1040 & 1111 & 9.7 & 6.6 & 31.5 & 0.13 \\
N & 507 & 774 & 17 & 4.6 & 27 & 0.26 & 1040 & 1259 & 4.8 & 1.6 & 14.6 & 0.31 \\
WQ & 1626 & 1626 & 0 & 0 & 0 & 0 & 719 & 719 & 0 & 0 & 0 & 0 \\
OQ & 1080 & 1492 & 2.5 & 0.2 & 4.5 & 0.53 & 1000 & 2146 & 2.2 & 0 & 0 & 0.82 \\
WQT & 1800 & 2070 & 2.4 & 0.3 & 3.4 & 0.44 & 1406 & 1406 & 0 & 0 & 0 & 0 \\
OQT & 850 & 1487 & 4.8 & 2 & 11 & 0.62 & 1600 & 2013 & 5.7 & 3.3 & 19.7 & 0.49 \\
\hline
\end{tabular}
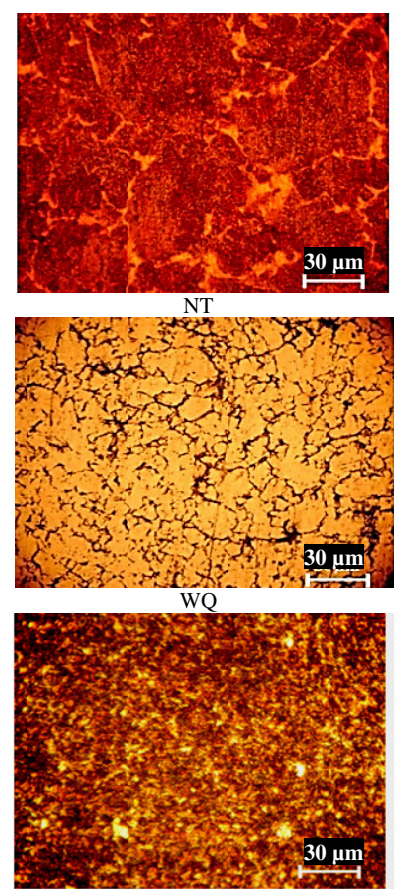

$\mathrm{OQ}$

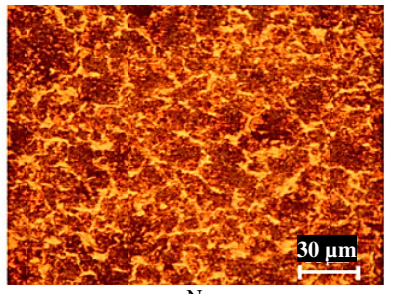

$\mathrm{N}$

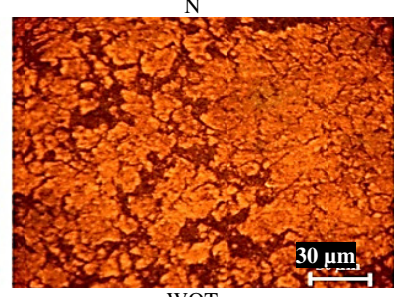

WQT

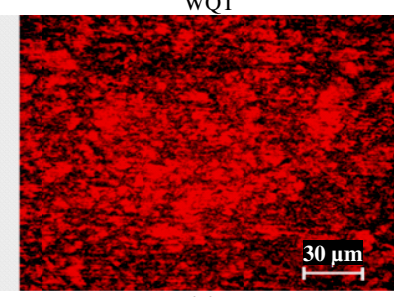

OQT

Fig. 3. Optical micrographs of the various microstructures for ISO C45 steel.

that the microstructure of the as received (untreated) $42 \mathrm{CrMo} 4$ steel (NT) is bainitic with finely divided carbide phases. Normalizing treatment $(\mathrm{N})$ induced a pearlitic microstructure. The remaining microstructures (WQ, WQT, OQ and OQT) were martensitic with various retained austenite. The conventional curves of traction are illustrated in Figure 5. The average values of strength and ductility properties are summarised in Table $4 . R_{m}, R p_{0.2}$, $A \%, Z \%$, and $Z_{u} \%$ respectively represent the ultimate strength, offset yield strength (proof stress), elongation at break, reduction in cross sectional area, and elongation due to necking. $n$ is the work hardening coefficient. The difference $\left(R_{m}-R_{p 0.2}\right)$ represents the hardening capacity. The engineering stress-strain diagrams of the various obtained microstructures show various mechanical behaviours. For ISO C45 steel, N and NT microstructures present a ductile behaviour while WQ is fragile. In addition, OQ and WQT microstructures present a quasifragile behaviour, whereas, OQT microstructure is little ductile. For ISO $42 \mathrm{CrMo} 4$ steel, N, NT and OQT microstructures present a ductile behaviour while WQ,
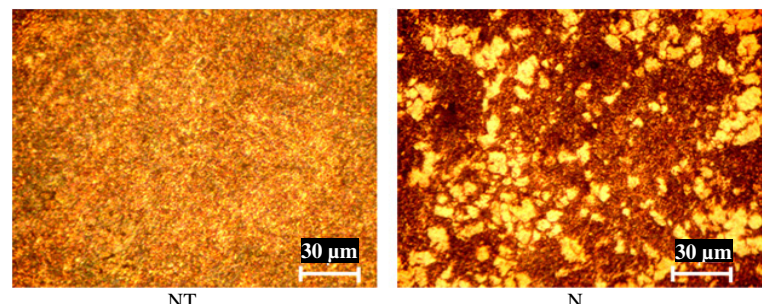

NT
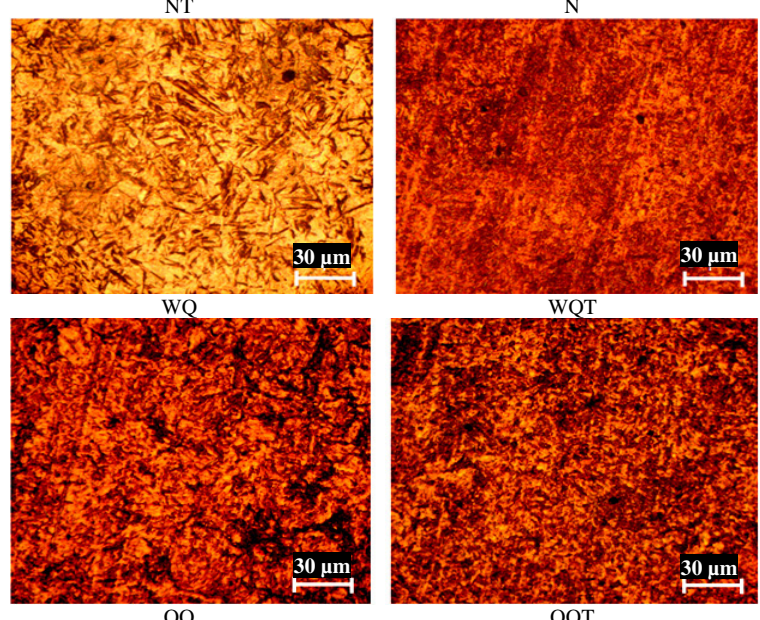

OQ

OQT

Fig. 4. Optical micrographs of the various microstructures for ISO $42 \mathrm{CrMo} 4$ steel.

WQT and OQ microstructures are fragile. Low tensile values obtained for $42 \mathrm{CrMo} 4 \mathrm{WQ}$ could be attributed to the brittleness of the samples, which are subjected to early fracture without reaching the maximum stress values. The treatment $\mathrm{OQ}$ conserved the same proof strength $\left(R p_{0.2}\right)$ but it has improved the ultimate strength by comparison with the untreated or the normalized specimens.

\subsection{Friction behaviour}

Figures 6 and 7 show the variation of the friction coefficient over sliding time for the various obtained microstructures of studied steels. Each experiment was repeated five times at minimum for each microstructure and test condition. The results show, for ISO C45 steel, that the martensitic microstructure WQ, which has the highest hardness and the lowest work-hardening properties, provided the highest stationary friction coefficient. The pearlitic microstructure OQT provided the lowest stationary friction coefficient. Despite N, NT and OQ 


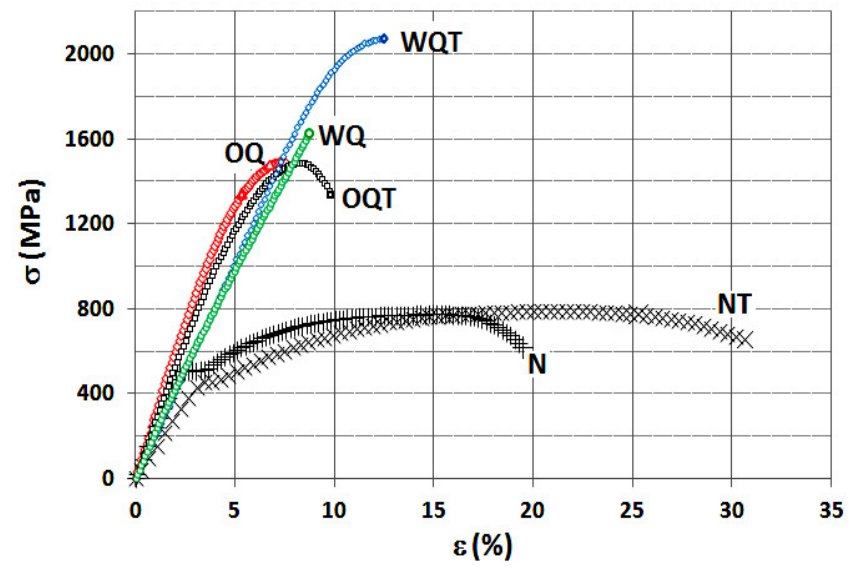

ISO C45

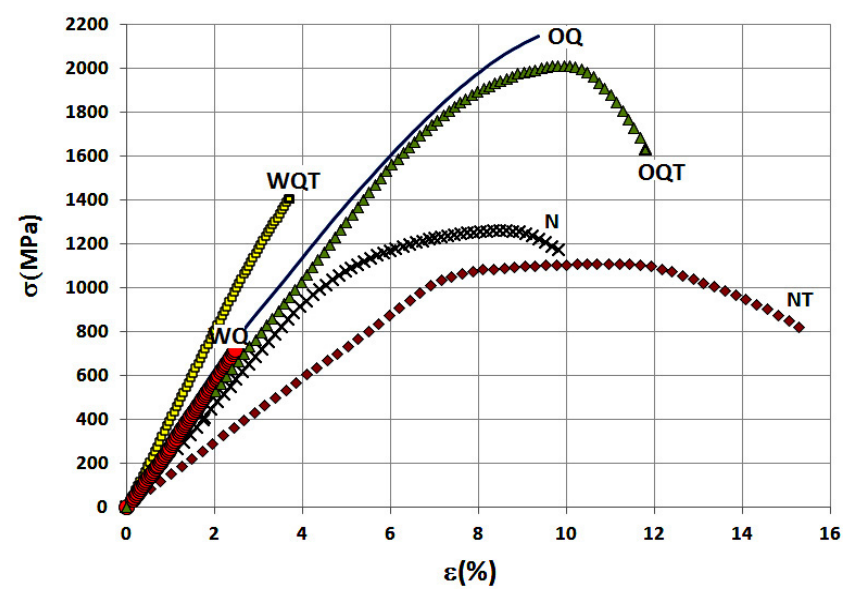

ISO 42CrMo4

Fig. 5. Stress-strain diagrams of tensile tests.

are pearlitic microstructures and have low hardnesses compared to WQT martensitic microstructure, they provided very close stationary friction coefficients. The results show, for ISO $42 \mathrm{CrMo} 4$ steel, that the martensitic microstructures WQ and OQ, which have the highest hardnesses and the lowest work-hardening properties, provided the highest stationary friction coefficients. The pearlitic microstructure NT provided the lowest stationary friction coefficient. Despite N is pearlitic microstructure and has low hardness compared to OQT and WQT martensitic microstructures, it provided very close stationary friction coefficients. These results confirm, for the two studied steels, that there is no correlation between friction properties and mechanical ones. A jump in the variation of the friction coefficient is noted for $\mathrm{N}$ and NT pearlitic microstructures (ISO C45 steel) after respectively 3000 and 4500 sliding cycles approximately. This phenomenon is due to the oxidation of contacting surfaces and wear debris at interface. Spinler indicated that the friction coefficient becomes higher if the surfaces are oxidised [12]. Table 5 shows that increasing normal load decreased the stationary friction coefficient for studied steels. This decrease was noted essentially when normal
Table 5. Variation of the stationary friction coefficient as function of normal load for $\mathrm{N}$ and $\mathrm{OQ}$ microstructures.

\begin{tabular}{ccccccc}
\hline & \multicolumn{3}{c}{ ISO } & C45/HSS & \multicolumn{3}{c}{ ISO } & $42 \mathrm{CrMo} 4 / \mathrm{HSS}$ \\
\hline$F(\mathrm{~N})$ & 22.7 & 42.7 & 62.7 & 22.7 & 42.7 & 62.7 \\
\hline $\mathrm{N}$ & 0.77 & 0.53 & 0.53 & 0.68 & 0.64 & 0.61 \\
$\mathrm{OQ}$ & 0.75 & 0.65 & 0.62 & 0.86 & 0.72 & 0.72 \\
\hline
\end{tabular}

Table 6. Stationary friction coefficient for the diverse studied microstructures of studied steels $(F=22.7 \mathrm{~N}-f=1 \mathrm{~Hz})$.

\begin{tabular}{ccccccc}
\hline Microstructure & NT & N & OQ & WQ & OQT & WQT \\
\hline ISO C45 & 0.72 & 0.75 & 0.75 & 0.88 & 0.56 & 0.78 \\
ISO 42CrMo4 & 0.57 & 0.66 & 0.85 & 0.86 & 0.68 & 0.72 \\
\hline
\end{tabular}

Table 7. Dissipated energy $E(\mathrm{~J})$ for the diverse microstructures of studied steels $(F=22.7 \mathrm{~N}-f=1 \mathrm{~Hz})$.

\begin{tabular}{ccccccc}
\hline Microstructure & NT & N & OQ & WQ & OQT & WQT \\
\hline ISO C45 & 996 & 1160 & 1140 & 1400 & 906 & 1210 \\
ISO 42CrMo4 & 871 & 1010 & 1350 & 1340 & 1070 & 1160
\end{tabular}

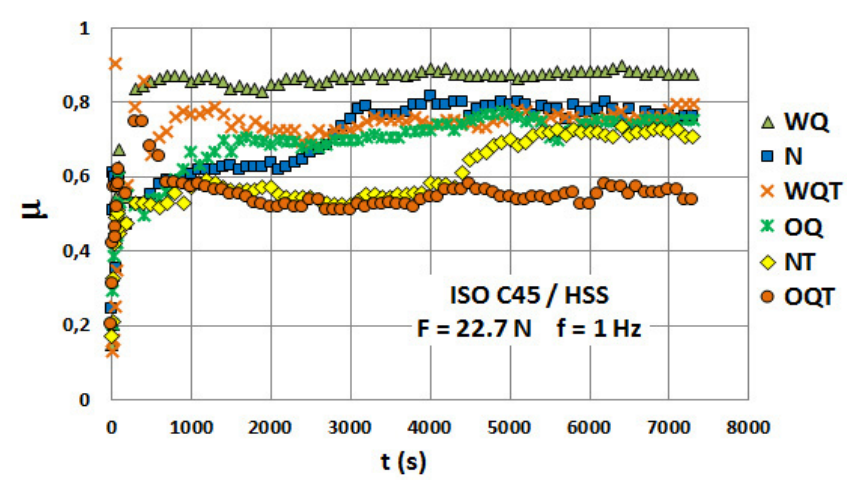

Fig. 6. Variation of the friction coefficient as function of sliding time for the diverse microstructures of ISO C45 steel.

load passed from $22.7 \mathrm{~N}$ to $42.7 \mathrm{~N}$ but when passing from $42.7 \mathrm{~N}$ to $62.7 \mathrm{~N}$ no significative variation was observed. Some authors have linked this decrease in the friction coefficient to the increase of the rubbing surface and the amount of wear debris [13]. Others have explained it by a probable alteration in the geometry of the contact surfaces, which is due to adhesive mechanisms of friction during the test [14]. Friction is a phenomenon, which dissipates mechanical energy in case of sliding (dynamic friction). Table 6 shows the effect of the various obtained microstructures on the stationary friction coefficient of the studied steels at $22.7 \mathrm{~N}$. Table 7 shows the effect of the various obtained microstructures on the friction energy of studied steels at $22.7 \mathrm{~N}$. The highest dissipated energy is obtained with the WQ microstructure for ISO C45 steel and with OQ microstructure for ISO 42CrMo4 steel. The lowest friction energy is obtained with OQT microstructure for ISO C45 steel and with NT microstructure for ISO $42 \mathrm{CrMo} 4$ steel. Results show that martensitic microstructures are more dissipative of energy than pearlitic ones. 


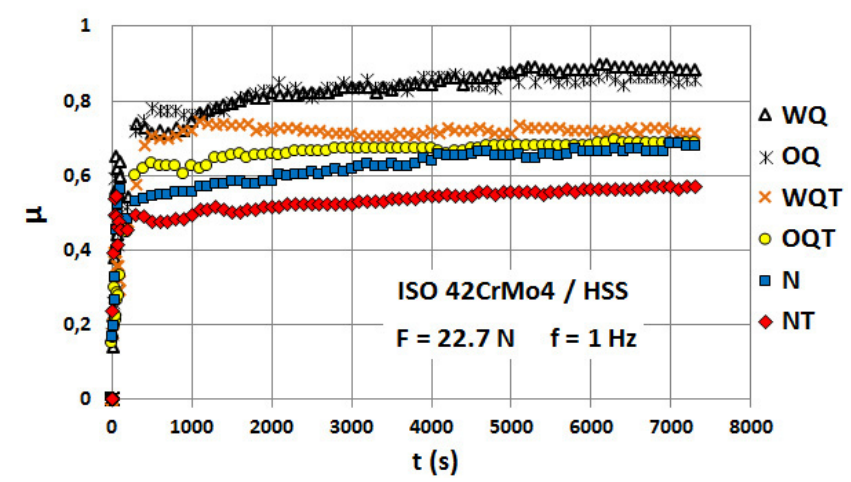

Fig. 7. Variation of the friction coefficient as function of sliding time for the diverse microstructures of ISO $42 \mathrm{CrMo} 4$ steel.

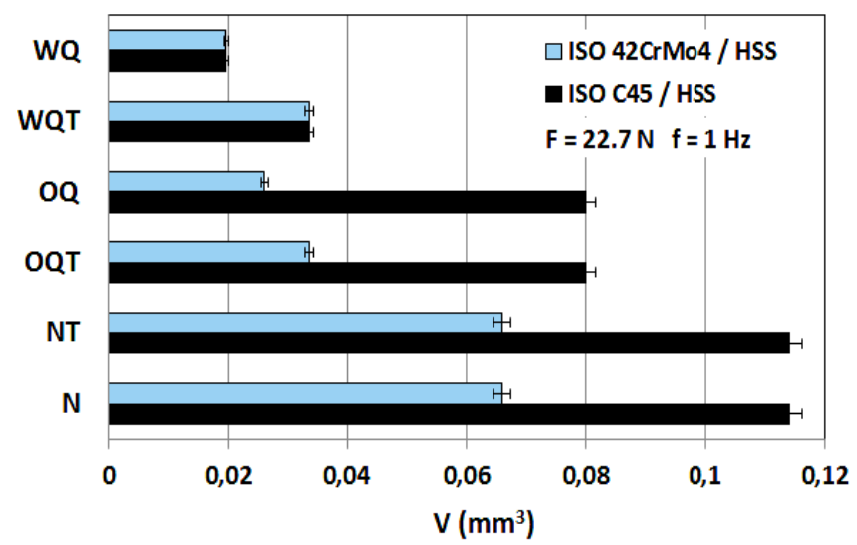

Fig. 8. Wear volume of the diverse microstructures for studied steels.

\subsection{Wear behaviour}

Figure 8 shows that the lowest wear volume was obtained with the martensitic microstructures WQ and WQT for ISO C45 steel and with WQ and OQ for ISO $42 \mathrm{CrMo} 4$ steel. These microstructures have the highest hardnesses. However, the highest wear volumes were obtained with the pearlitic microstructures N and NT for the two studied steels. These microstructures have the lowest hardnesses. Thus, increasing the hardness increases the resistance to abrasive wear. Figures 9 and 10 show that increasing of the normal load increased significantly the wear volume for the two studied steels. Figure 11 shows that the highest values of the wear coefficient $\mathrm{K}$ were usually obtained with the microstructures NT and $\mathrm{N}$, while the lowest ones were obtained by microstructures WQ and WQT for ISO C45 steel, WQ, and OQ for ISO $42 \mathrm{CrMo} 4$ steel. Das et al. indicated that the Archard wear coefficient $\mathrm{K}$ is the inverse of the wear resistance [3]. Bensley et al. adopted the same definitions [15]. Thus, if the wear coefficient increases wear resistance decreases. Figures 12 and 13 show that increasing normal load usually increases the wear coefficient. Results show that when normal load exceeds $42.7 \mathrm{~N}$ the kinetics of wear changed. Except the case of OQ microstructure relative to ISO $42 \mathrm{CrMo} 4$ steel, wear coefficient increases significantly

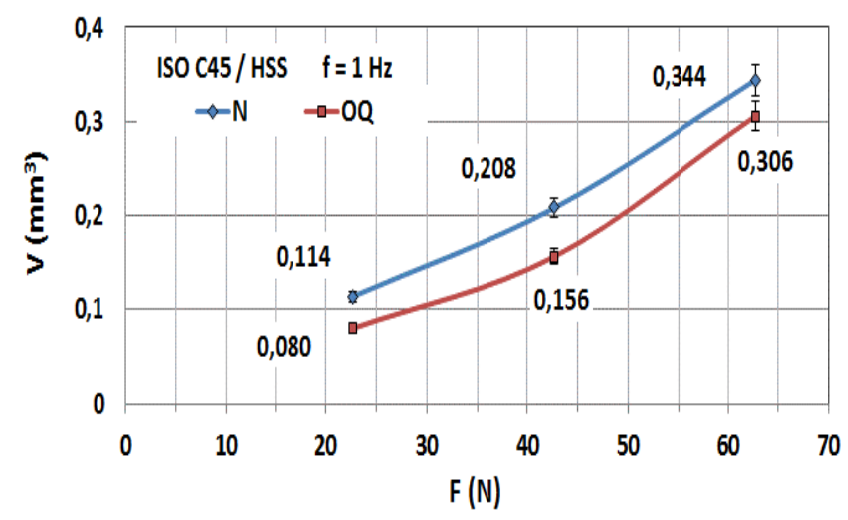

Fig. 9. Variation of the wear volume as function of normal load for $\mathrm{N}$ and OQ microstructures (ISO C45 steel).

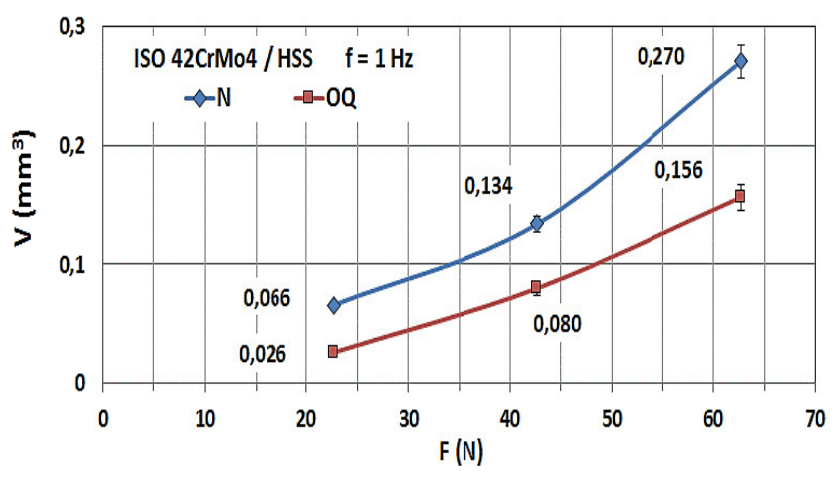

Fig. 10. Variation of the wear volume as function of normal load for $\mathrm{N}$ and OQ microstructures (ISO 42CrMo4 steel).

when load exceeds 42.7 N. Figures 12 and 13 show also that wear processes are affected by the response of the microstructure under the tribological test conditions. Indeed, for C45 steel wear coefficient of microstructure $\mathrm{N}$ at $22.7 \mathrm{~N}$ is higher than which of microstructure OQ. Then when normal load reached $42.7 \mathrm{~N}$ the wear coefficients became similar and when it reached $62.7 \mathrm{~N}$, wear coefficient of microstructure OQ became higher than which of microstructure N. For $42 \mathrm{CrMo} 4$ steel similar result was obtained at $22.7 \mathrm{~N}$ but when normal load reached $42.7 \mathrm{~N}$ or $62.7 \mathrm{~N}$, the obtained wear coefficients showed inversed behavior but they has comparable values. These variations in the wear kinetics can be attributed to the variation in the wear mechanisms because of the effect of increasing normal load on the mechanical behavior of the wear debris at interface. Microstructural constituents, such as bainite, martensite, pearlite and carbides lead to different tribological behaviors and wear mechanisms. Martensitic microstructures induce generally oxidative wear mechanisms, bainitic microstructures can produce abrasive ones (micropolishing) and pearlitic ones can lead to adhesive wear mechanisms (plasticity-dominated wear). The SEM micrographs (Fig. 14) of the pearlitic microstructures identify an abrasive wear mechanism that dominates. This mechanism is characterised by wear streaks obtained by plowing or mainly by intermediate particles 


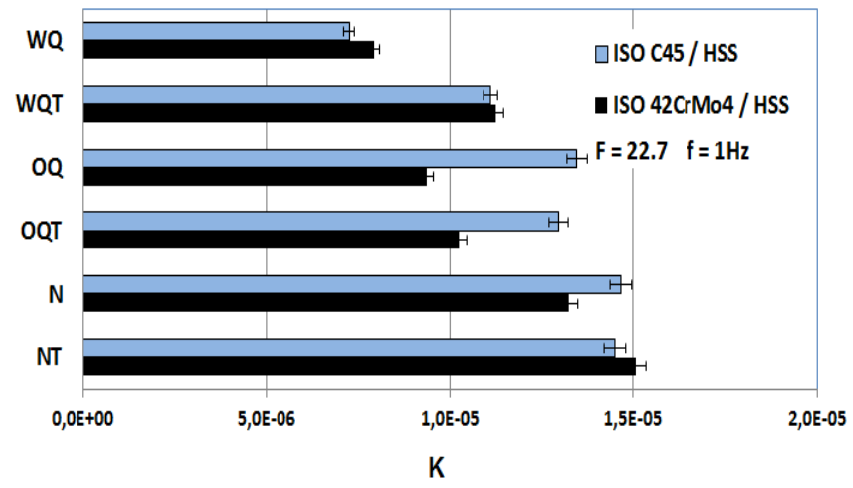

Fig. 11. Wear coefficient of the diverse microstructures for studied steels.

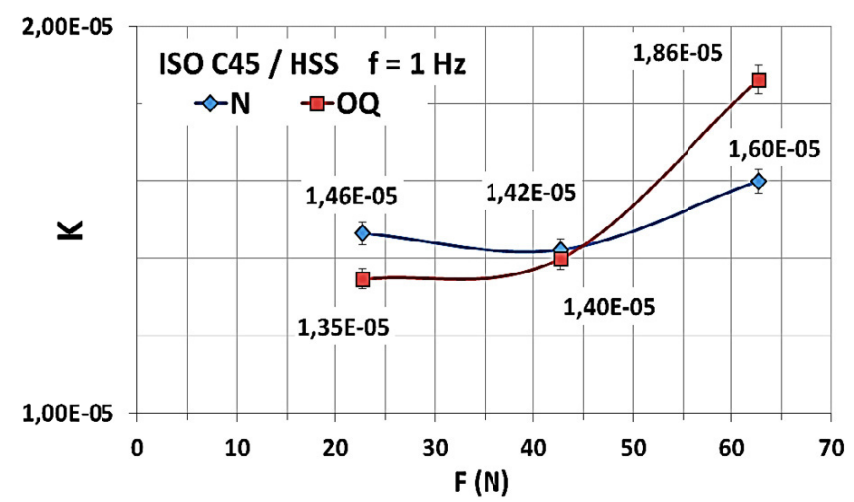

Fig. 12. Variation of the wear coefficient as function of normal load for $\mathrm{N}$ and OQ microstructures (ISO C45 steel).

(wear debris) which are work-hardened because of contact pressures and have become harder than the contact surfaces. This microstructure is characterised by an accentuated wear illustrated by a high amount of debris and a high depth and density of wear streaks. The SEM micrographs of the martensitic microstructures identify essentially an oxidative wear mechanism, which is dominant in the case of WQ microstructure and is characterised by the oxidation of the rubbing surfaces. A wear resistance illustrated by small amount of wear debris, shallow depth and low density of wear stripes was also noted for WQ microstructure. Figure 15 shows a wear facies of the HSS counterpart sliding against ISO C45 steel (WQ microstructure). The scratches are not due to an abrasive wear mechanism but they are due to the initial preparation of sample surface. The debris of wear with white color in the micrographs are carbides. The presence of carbides, in the interface, provoke increased wear rates, standing as protrusions and acting as sharp cutting edges against softer counterfaces, or having detached out from the matrix and behaving as third body abrasive particles. Because the hardness of HSS counterbody is very high $(870 \mathrm{HV})$, only the tested steels (carbon or low-alloy) are subjected to highest wear.

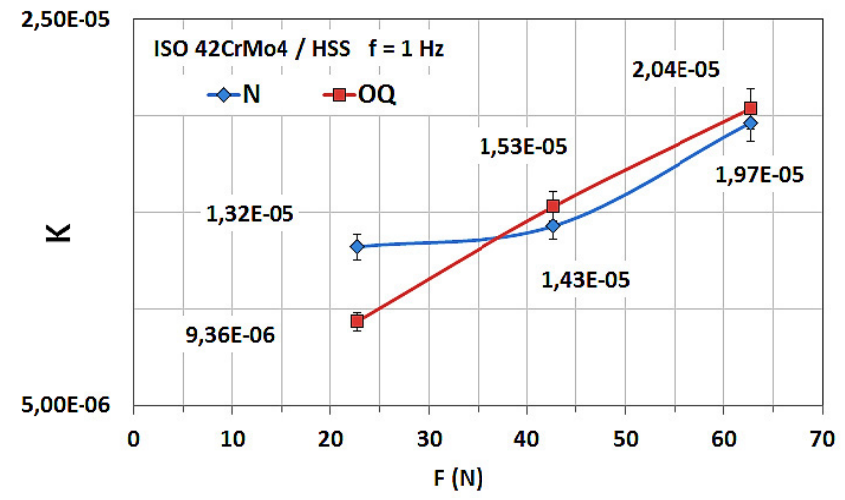

Fig. 13. Variation of the wear coefficient as function of normal load for $\mathrm{N}$ and OQ microstructures (ISO 42CrMo4 steel).
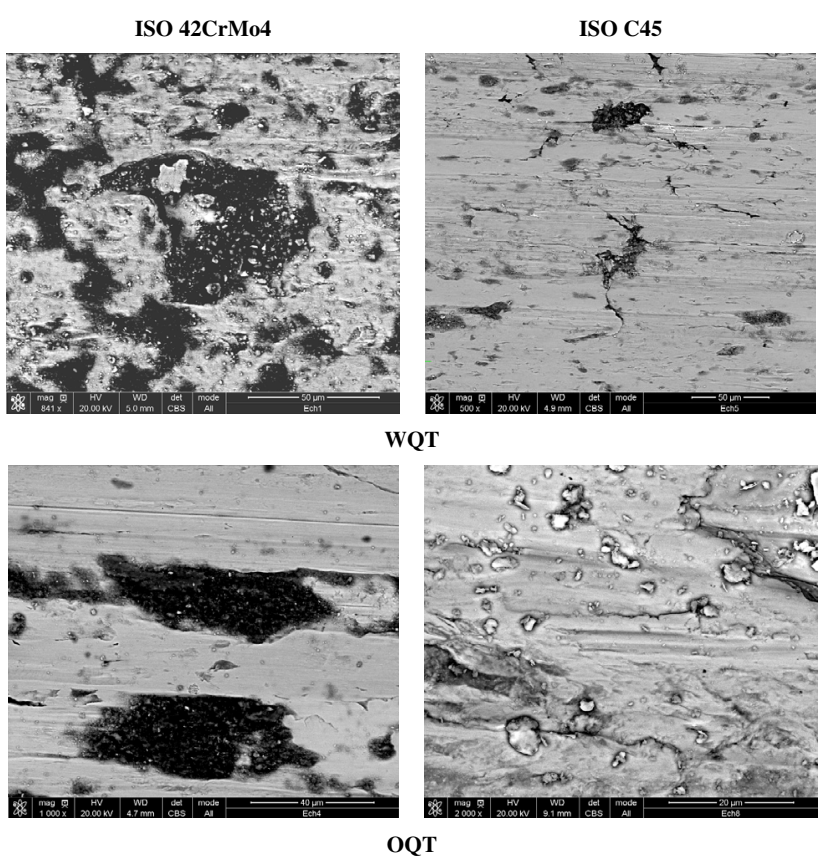

Fig. 14. SEM micrographs of the worn surfaces for WQT and OQT microstructures $(F=22.7 \mathrm{~N}-f=1 \mathrm{~Hz})$.

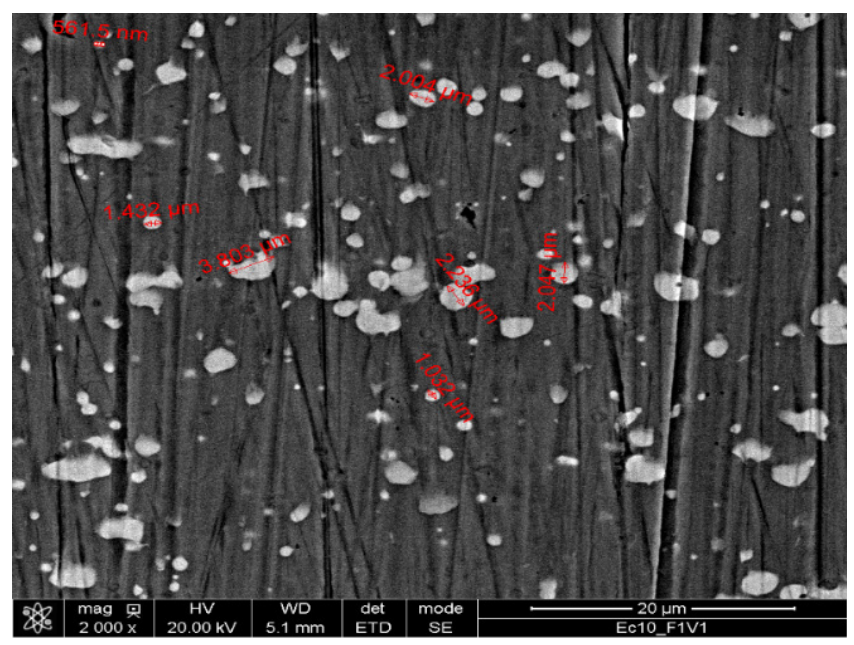

Fig. 15. SEM micrograph of the worn surface for HSS counterpart $(F=22.7 \mathrm{~N}-f=1 \mathrm{~Hz})$. 


\section{Conclusions}

This work investigates the effect of various microstructures on the tribological properties of ISO C45 carbon steel and ISO 42CrMo4 low-alloy steel. Results showed that WQ microstructure yielded to the highest friction properties. On the contrary, the lowest energy and friction coefficient do not depend on a specific microstructure. There is no obvious correlation between friction properties and hardness or work hardening properties. Oxidation of worn surfaces increases the friction coefficient for all studied microstructures. Abrasive and oxidative wear mechanisms were identifed for the different microstructures. The first mechanism is essentially characteristic of pearlitic microstructures while the latest is particularly characteristic of martensitic microstructures. Martensitic microstructures gave generally the lowest volumes and coefficients of wear while pearlitic microstructures gave the highest ones. These tribological properties decrease, in general, when hardness increases. However, no correlation appears between wear properties and work hardening ones. Increasing of normal load decreased the friction coefficient but increased generally wear volume and wear coefficient.

\section{References}

[1] D. Rai, B. Singh, J. Singh, Characterisation of wear behaviour of different microstructures in $\mathrm{Ni}-\mathrm{Cr}-\mathrm{Mo}-\mathrm{V}$ steel, Wear 263 (2007) 821-829

[2] M.H. Shaeri, H. Saghafian, S.G. Shabestari, Effect of heat treatment on microstructure and mechanical properties of Cr-Mo steels (FMU-226) used in mills liner, Mater. Design 34 (2012) 192-200

[3] D. Das, A.K. Dutta, K.K. Ray, Correlation of microstructure with wear behaviour of deep cryogenically treated AISI D2 steel, Wear 267 (2009) 1371-1380
[4] S. Kumar, A. Bhattacharyya, D.K. Mondal, K. Biswas, J. Maity, Dry sliding wear behaviour of medium carbon steel against an alumina disk, Wear 270 (2011) 413-421

[5] V. Abouei, H. Saghafian, Sh. Kheirandish, Effect of microstructure on the oxidative wear behaviour of plain carbon steel, Wear 262 (2007) 1225-1231

[6] A. Garcia, A. Varela, L. Garcia, M.C. Rio, S. Naya, M. Suarez, Comparing the tribological behaviour of an austenitic steel subjected to diverse thermal treatments, Wear 258 (2005) 203-207

[7] Y. Wang, T. Lei, J. Liu, Tribo-metallographic behavior of high carbon steels in dry sliding II. Microstructure and wear, Wear 231 (1999) 12-19

[8] J.L. Fanchon, Guide des sciences et technologies industrielles, Nathan, 2001

[9] A. Ramalho, J.C. Miranda, The relationship between wear and dissipated energy in sliding systems, Wear 260 (2006) 361-367

[10] J.F. Archard, Contact and rubbing of flat surfaces, J. Appl. Phys. 24 (1953) 981-988

[11] M.J. Perez, M.M. Cisneros, H.F. Lopez, Wear resistance of $\mathrm{Cu}-\mathrm{Ni}-\mathrm{Mo}$ austempered ductile iron, Wear 260 (2006) $879-885$

[12] G. Spinler, Conception des machines, Principes et applications, 1 statique, 2002, p. 61

[13] M.A. Chowdhury, M.K. Khalil, D.M. Nuruzzaman, M.L. Rahaman, The effect of sliding speed and normal load on friction and wear property of aluminum, IJMME-IJENS 11 (2011) 53-57

[14] G. Pantazopoulos, P. Psyllaki, D. Kanakis, S. Antoniou, K. Papadimitriou, J. Sideris, Tribological properties of a liquid nitrocarburised special purpose cold work tool steel, Surf. Coat. Technol. 200 (2006) 5889-5895

[15] A. Bensely, A. Prabhakaran, D. Mohan Lal, G. Nagarajan, Enhancing the wear resistance of case carburized steel (En 353) by cryogenic treatment, Cryogenics 45 (2006) $747-754$ 